\title{
Trans-Colostomy Placement of a Button Gastrostomy Tube for Malignant Bowel Obstruction in Patients with Peritoneal Carcinomatosis
}

\author{
Mizuki Ozawa ${ }^{1}$ Miyuki Sone ${ }^{1}$ Yasuaki Arai ${ }^{1}$ Shunsuke Sugawara ${ }^{1}$ Chihiro Itou ${ }^{1}$ Shintaro Kimura ${ }^{1}$ \\ Daisuke Okamoto $^{2}$ Masahiko Kusumoto ${ }^{1}$
}

${ }^{1}$ Department of Diagnostic Radiology, National Cancer Center Hospital, Chuo-ku, Tokyo, Japan

${ }^{2}$ Department of Radiology, Saiseikai Fukuoka General Hospital, Chuoku, Fukuoka, Japan

Address for correspondence Mizuki Ozawa, MD, Department of Diagnostic Radiology, National Cancer Center Hospital, 5-1-1, Tsukiji, Chuo-ku, Tokyo 1040045, Japan (e-mail: mizukiozawa0717@gmail.com).

Arab J Intervent Radiol 2021;5:106-109.

\begin{abstract}
Purpose The aim of the study is to evaluate the feasibility, safety, and efficacy of the trans-colostomy placement of a button gastrostomy tube for patients with malignant bowel obstruction due to peritoneal carcinomatosis.

Material and Methods Data from seven consecutive patients who presented with malignant bowel obstruction due to peritoneal carcinomatosis involving the colostomy site and underwent trans-colostomy button gastrostomy tube placement between 2013 and 2020 were retrospectively reviewed. We assessed technical and clinical success rate, procedure time, duration of improvement, and complication rate.

Results The technical success rate of the trans-colostomy button gastrostomy tube

Keywords

- malignant bowel obstruction

- button gastrostomy tube

- peritoneal carcinomatosis placement was $100 \%$, and average procedure time was 25 minutes. Clinical symptoms of malignant bowel obstruction resolved in four out of seven (57\%) patients. Average duration of improvement in the four patients with clinical success was 170.8 days. There were no complications associated with the procedure.

Conclusion Trans-colostomy button gastrostomy tube placement might be a safe and feasible treatment option for patients with malignant bowel obstruction due to peritoneal carcinomatosis.
\end{abstract}

\section{Introduction}

Malignant bowel obstruction (MBO) is a frequent complication in patients with advanced malignancy. Nausea and vomiting arising from gastrointestinal obstruction are often refractory to medical treatments and impair patients' quality of life (QOL).
The National Comprehensive Cancer Network guidelines recommend both medical and non-medical treatment approaches for $\mathrm{MBO}^{1}$ Since $\mathrm{MBO}$ is a complex palliative care problem, diverse strategies must be employed according to the patient's physical condition and preferences.

Although surgical treatment can be a beneficial option, it poses the risk of high morbidity and substantial hospitaliza- published online January 15, 2022
DOI https://doi.org/

10.1055/s-0041-1741372.

ISSN 2542-7075. (c) 2022. The Pan Arab Interventional Radiology Society. All rights reserved.

This is an open access article published by Thieme under the terms of the Creative Commons Attribution-NonDerivative-NonCommercial-License, permitting copying and reproduction so long as the original work is given appropriate credit. Contents may not be used for commercial purposes, or adapted, remixed, transformed or built upon. (https://creativecommons.org/ licenses/by-nc-nd/4.0/)

Thieme Medical and Scientific Publishers Pvt. Ltd., A-12, 2nd Floor, Sector 2, Noida-201301 UP, India 
tion relative to the patient's remaining survival time. ${ }^{2}$ Furthermore, surgical treatments are not generally indicated for patients in a poor general condition.

Peritoneal carcinomatosis involving the colostomy site is rare but may cause $\mathrm{MBO}^{3}$ The colostomy site would be favorable to manage with interventional radiology (IR) techniques given the superficial location, allowing for ease of approach. The use of self-expanding metallic stents (SEMS) has been reported as an IR treatment for colostomy obstruc$\operatorname{tion}^{4,5}$; however, the technique has not been fully established to prevent inadvertent removal due to peristalsis. Foley catheter insertion through colostomy has been reported for temporary intestinal decompression ${ }^{6}$ and has been used in daily clinical practice. Given the requirement of a large diameter for effective drainage of feces, the use of a gastrostomy tube with anti-dislodgement mechanisms, such as a button gastrostomy tube, may be suitable.

We aimed to retrospectively evaluate the feasibility, safety, and efficacy of the placement of a button gastrostomy tube as a decompression tube in colostomy obstruction due to peritoneal carcinomatosis.

\section{Materials and Methods}

Institutional review board approval and waiver of the requirement for informed consent to participate in this retrospective study were obtained. All patients provided written informed consent for undergoing the procedure.

Data of seven consecutive patients (three male/four female; median age 59.1 years) who presented with colostomy obstruction due to peritoneal carcinomatosis and underwent button gastrostomy tube placement between 2013 and 2020 were reviewed. Three of them had gastric cancer while the remaining four had colon cancer.

Colostomy obstruction was diagnosed using computed tomography. A button gastrostomy tube (Kangaroo, Cardinal Health Japan, Tokyo, Japan) was used as decompression tube with calibers ranging between 16 and $24 \mathrm{~F}$ and lengths from
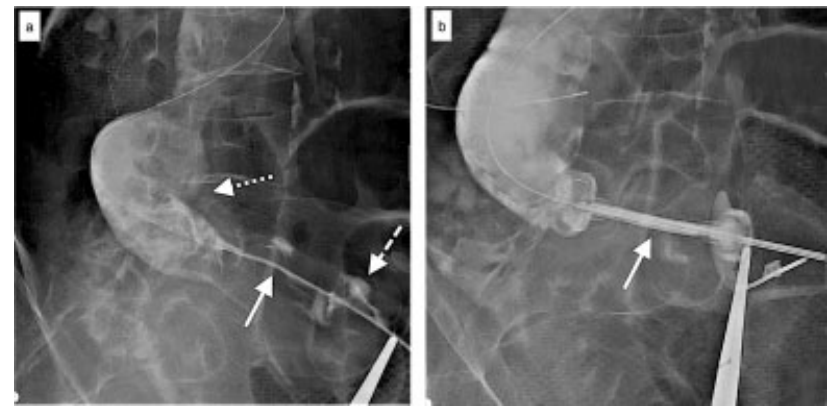

Fig. 2 (a) Fluoroscopic view showing the colostomy (white dashed arrow), stenosed segment (white solid arrow), and dilation of the oralintestinal tract (white dotted arrow). (b) The button gastrostomy tube was placed in the stenosed segment (white solid arrow).

1.5 to $5.5 \mathrm{~cm}$. It had bumpers to prevent anti-dislodgement mechanism. Before placement, the one-way valve inside the tube was removed using forceps (-Fig. $\mathbf{1}$ ).

The colostomy occlusion was crossed using a $6.5 \mathrm{~F}$ seeking catheter (Hanako Medical, Tokyo, Japan) and a hydrophilic guidewire (Radifocus Guidewire M; Terumo, Tokyo, Japan), and the length of the occlusion was measured (refer to the length of guidewire under fluoroscopic guidance). Subsequently, a button gastrostomy tube according to the length of the occlusion and degree of stenosis (-Fig. 2) was placed over the guidewire. All procedures were performed under local anesthesia. After placement of the tube, the colostomy and tube were covered with a pouch using a standard management technique.

The following outcomes were evaluated in this study: procedure time, measured as the time from sterilization to completion of tube placement; technical success, evaluated as successful tube placement through the colostomy; clinical success, evaluated as improvement of clinical symptoms of $\mathrm{MBO}$; duration of improvement, measured as the time from improvement of symptoms to relapse or as the time until the latest hospital visit or date of death in the patients without
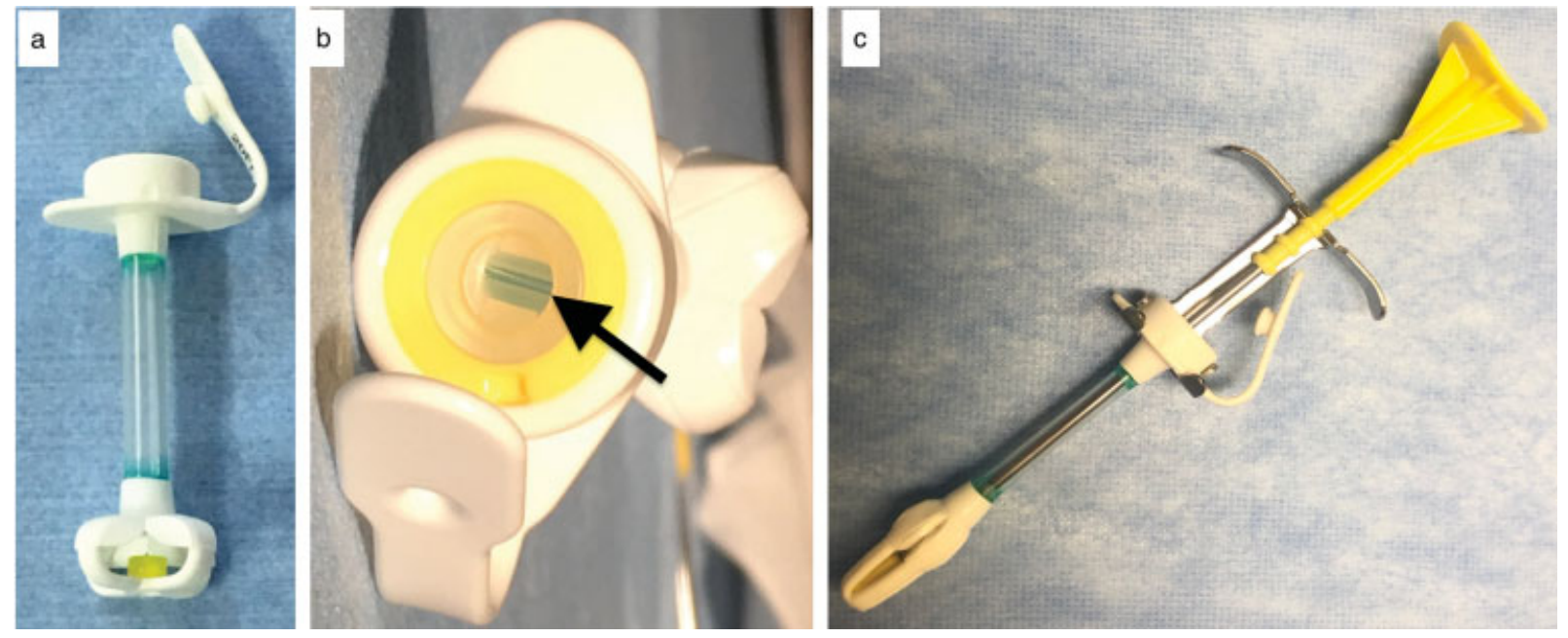

Fig. 1 (a) Button gastrostomy tube with a caliber of $16 \mathrm{~F}$ to $24 \mathrm{~F}$ and length of 1.5 to $5.5 \mathrm{~cm}$, equipped with a bumper to prevent it from falling out. (b) The non-return valve (black solid arrow) is removed before placement of button gastroscopy tube. (c) The bumper is stretched using an obturator to break through the stenosis. 
Table 1 Demographic and treatment details of the seven patients

\begin{tabular}{|c|c|c|c|c|c|c|c|c|}
\hline \multirow{3}{*}{ No } & \multicolumn{8}{|c|}{ Patient demographics and treatment details } \\
\hline & \multicolumn{2}{|c|}{ Patient demographics } & \multicolumn{6}{|c|}{ Treatment details } \\
\hline & Age/Sex & Primary & $\begin{array}{l}\text { Length } \\
\text { of stenosis }\end{array}$ & Tube size & $\begin{array}{l}\text { Procedure } \\
\text { time }\end{array}$ & $\begin{array}{l}\text { Technical } \\
\text { success }\end{array}$ & $\begin{array}{l}\text { Clinical } \\
\text { success }\end{array}$ & $\begin{array}{l}\text { Follow up } \\
\text { duration }\end{array}$ \\
\hline 1 & $52 / \mathrm{M}$ & Gastric cancer & $5 \mathrm{~cm}$ & $24 \mathrm{~F} / 5 \mathrm{~cm}$ & $70 \min$ & Yes & Yes & $136 \mathrm{~d}$ \\
\hline 2 & $71 / \mathrm{F}$ & Colorectal cancer & $5 \mathrm{~cm}$ & $24 \mathrm{~F} / 5 \mathrm{~cm}$ & $10 \min$ & Yes & Yes & $126 \mathrm{~d}$ \\
\hline 3 & $71 / \mathrm{M}$ & Gastric cancer & $5 \mathrm{~cm}$ & $20 \mathrm{~F} / 5 \mathrm{~cm}$ & $20 \mathrm{~min}$ & Yes & Yes & $89 d$ \\
\hline 4 & $60 / \mathrm{F}$ & Gastric cancer & $4.5 \mathrm{~cm}$ & $20 \mathrm{~F} / 5 \mathrm{~cm}$ & $40 \mathrm{~min}$ & Yes & No & $27 d$ \\
\hline 5 & $38 / \mathrm{F}$ & Colorectal cancer & $4.5 \mathrm{~cm}$ & $20 \mathrm{~F} / 5 \mathrm{~cm}$ & $10 \min$ & Yes & Yes & $446 d$ \\
\hline 6 & $56 / \mathrm{F}$ & Colorectal cancer & $1 \mathrm{~cm}$ & $20 \mathrm{~F} / 5 \mathrm{~cm}$ & $10 \min$ & Yes & No & $642 d$ \\
\hline 7 & $66 / \mathrm{M}$ & Colorectal cancer & $5 \mathrm{~cm}$ & $20 \mathrm{~F} / 5 \mathrm{~cm}$ & $15 \min$ & Yes & No & $47 d$ \\
\hline
\end{tabular}

relapse; and complications, categorized according to the Clavien-Dindo classification. ${ }^{7}$

\section{Results}

Trans-colostomy tube placement was successfully performed in all cases. The length of the stenosed segment ranged between 1 to $5 \mathrm{~cm}$ (-Table 1). The tube used was $20 \mathrm{~F}$ or $24 \mathrm{~F}$ with a length of 5 or $5.5 \mathrm{~cm}$. Average procedure time was 25 minutes.

Clinical success was achieved in four (57\%) patients. Average duration of improvement in the four patients with clinical success was 170.8 days. One of the three patients without clinical success had multiple stenoses, and the other two patients had high-viscosity intestinal contents.

There were no complications associated with the procedure. Tube dislodgment occurred in two patients. Additional decompression was needed on the same day for one patient. Another patient maintained symptom improvement for 2 months; however, trans-colostomy tube placement was needed following this period owing to symptom relapse.

\section{Discussion}

There have been few reports of non-medication approaches for the treatment of colostomy obstruction due to peritoneal
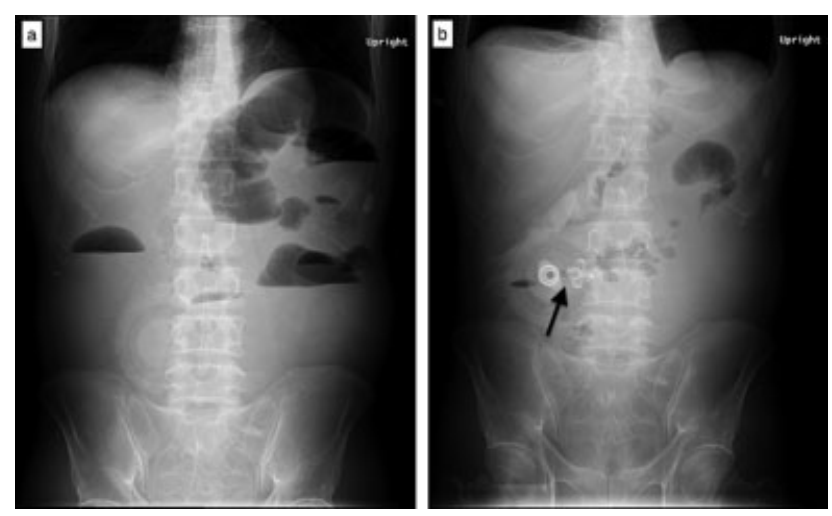

Fig. 3 (a) Abdominal X-ray image before procedure shows air-fluid level suggesting intestinal obstruction. (b) In the abdominal X-ray image after the placement of button gastrostomy tube (black solid arrow), air-fluid level disappeared. carcinomatosis. In two case reports of SEMS placement, improvement of the intestinal obstruction symptoms was observed. ${ }^{4,5}$ However, SEMS has an inevitable disadvantage of dislodgment, and the effectiveness has not been fully evaluated.

In this study, trans-colostomy placement of a button gastrostomy tube demonstrated a technical success rate of $100 \%$ and no procedural complications. Thus, this procedure is considered to have good feasibility and safety. A clinical success rate of $57 \%$ is not very high but may be acceptable given the absence of definitive treatments for these patients (-Fig. 3). Furthermore, the duration of improvement (170.8 days) in the patients with clinical success is relatively long. Factors affecting a lack of improvement in the symptoms include multiple intestinal stenoses and high viscosity of intestinal contents. Although the button gastrostomy tubes may be advantageous for use as decompression tubes owing to the wide calibers and the bumpers as an anti-dislodgement mechanism, further improvement of the device is warranted.

This study has several limitations including a small sample size, retrospective design, and treatment being performed in a single center; device optimization was also not examined. Furthermore, button gastrostomy tubes are not uniformly available worldwide, though these are widely used in Japan. Moreover, there is no established method for evaluating clinical efficacy for comparison with previous reports.

\section{Conclusion}

Button gastrostomy tube placement for colostomy obstruction may have good feasibility and safety and may be effective in maintaining QOL for patients with $\mathrm{MBO}$ due to stenosis of the colostomy site and in whom intestinal contents are not highly viscous.

\section{Ethical Approval}

All procedures performed in studies involving human participants were in accordance with the ethical standards of the institutional and/or national research committee and with the 1964 Helsinki declaration and its later 
amendments or comparable ethical standards. For this type of study formal consent is not required. This retrospective study was approved by the Institutional Ethics Committee.

\section{Informed Consent}

This study has obtained IRB approval from the Institutional Ethics Committee and the need for informed consent was waived.

\section{Consent for Publication}

For this type of study consent for publication is not required.

\section{Funding}

This study was funded by the National Cancer Center under the National Cancer Center Research and Development Fund (grant number 2020-J-3). The funding body had no role in the design of the study; collection, analysis, or interpretation of data; or in writing the manuscript.

\section{Conflict of Interest}

None declared.

\section{Acknowledgment}

The authors would like to thank Editage (www.editage. com) for the English language editing.

\section{References}

1 National Comprehensive Cancer Network. NCCN clinical practice guidelines in oncology palliative care. version 1; 2020. Accessed February 07, 2020 at: http://www.nccn.org/professionals/ physician_gls/PDF/palliative.pdf

2 Reilly WT, Nelson H, Schroeder G, Wieand HS, Bolton J, O'Connell MJ. Wound recurrence following conventional treatment of colorectal cancer. A rare but perhaps underestimated problem. Dis Colon Rectum 1996;39(02):200-207

3 Paul Olson TJ, Pinkerton C, Brasel KJ, Schwarze ML. Palliative surgery for malignant bowel obstruction from carcinomatosis: a systematic review. JAMA Surg 2014;149(04):383-392

$4 \mathrm{Kim}$ WH, Kwon CI, Kim JW, Lee C. Insertion of a self-expanding metal stent for a stomal stenosis. Endoscopy 2012;44(2, suppl 2 UCTN):E143-E144

5 van Gils NA, Cornelissen JGHM, Tan ACITL. A metal stent in a colostomy obstruction. GE Port J Gastroenterol 2018;25(04):214-215

6 Ray K, McFall M. Large bowel enema through colostomy with a Foley catheter: a simple and effective technique. Ann R Coll Surg Engl 2010;92(03):263

7 Dindo D, Demartines N, Clavien PA. Classification of surgical complications: a new proposal with evaluation in a cohort of 6336 patients and results of a survey. Ann Surg 2004;240(02):205-213 